\title{
Retraction Note: Discussion on ecological design and construction of river landscape based on fine-grained image classification
}

\author{
XueYang $\mathrm{Li}^{1} \cdot$ Xiaozhao Cao $^{1}$
}

Published online: 2 December 2021

(c) Saudi Society for Geosciences 2021

Retraction Note: Arabian Journal of Geosciences (2021) 14: 1523 https://doi.org/10.1007/s12517-021-07843-4

The Editor-in-Chief and the Publisher have retracted this article because the content of this article is nonsensical. The peer review process was not carried out in accordance with the Publisher's peer review policy. Author Xiaozhao Cao has not responded to correspondence regarding this retraction. The Publisher has not been able to obtain a current email address for author Xueyang Li.

The original article can be found online at https://doi.org/10.1007/ s12517-021-07843-4.

Xiaozhao Cao

lixyang2019@163.com

1 Sichuan Tourism University, Chengdu 610100, Sichuan,

China 